\title{
Efficacy of clarithromycin on biofilm formation of methicillin-resistant Staphylococcus pseudintermedius
}

\author{
Matthew DiCicco ${ }^{1}$, Suresh Neethirajan ${ }^{1 *}$, Ameet Singh ${ }^{2}$ and J Scott Weese ${ }^{3}$
}

\begin{abstract}
Background: Surgical site infections (SSIs) caused by biofilm-forming methicillin-resistant Staphylococcus pseudintermedius (MRSP) have emerged as the most common hospital-acquired infections in companion animals. No methods currently exist for the therapeutic remediation of SSIs caused by MRSP in biofilms. Clarithromycin (CLA) has been shown to prevent biofilm formation by Staphylococcus aureus. This study aims to assess the in vitro activity of CLA in eradicating MRSP biofilm formation on various materials.

Results: Quantitative assay results $(P=0.5126)$ suggest that CLA does not eradicate MRSP biofilm formation on polystyrene after $4-24 \mathrm{~h}$ growth periods. Scanning electron micrographs confirmed that CLA did not eradicate MRSP biofilm formed on orthopaedic implants.

Conclusions: By determining the in vitro characteristics and activities of MRSP isolates alone and against antibiotics, in vitro models of biofilm related infections can be made. In vitro data suggests that CLA does not effectively eradicate S. pseudintermedius biofilms in therapeutic doses.
\end{abstract}

Keywords: MRSP, S. pseudintermedius, Methicillin-resistant, Therapeutic, Bacteria, Biofilm, Macrolide, Clarithromycin

\section{Background}

Surgical site infections (SSIs) are an inherent risk of any surgical procedure and can lead to morbidity, prolonged hospitalization, client frustration, frustration of medical caregivers, and increased treatment costs in veterinary medicine [1] and have been reported as a complication of $0.8 \%$ to $18.1 \%$ of operations in dogs and cats, depending on the surgical classification [2-4]. They are of particular concern with implanted biomaterials such as orthopaedic implants, suture material, and indwelling medical devices.

Staphylococcus pseudintermedius is an opportunistic pathogen that can be found on the skin or in the ears, oral cavity, intestinal tract or other non-sterile sites of a large percentage of healthy dogs [5,6]. In addition to being one of the leading causes of SSIs, staphylococci have a tendency to acquire resistance to antimicrobial

\footnotetext{
* Correspondence: sneethir@uoguelph.ca

'School of Engineering, University of Guelph, Ontario, Canada

Full list of author information is available at the end of the article
}

agents [7]. Of particular concern is methicillin-resistance, which confers resistance to all beta-lactam antimicrobials. Methicillin-resistant S. pseudintermedius (MRSP) has rapidly emerged in companion animals and MRSP infections are being reported with increasing frequency in veterinary hospitals, becoming a major cause of pyoderma and SSIs in dogs [8-12]. MRSP infections are a tremendous concern in companion animals as they are challenging to eradicate being recalcitrant to traditional antimicrobial therapy, both due to their resistance to beta-lactam antimicrobials and because they typically have also acquired resistance to various other antimicrobial classes [1]. Reasons for the rapid emergence of MRSP are not well understood, however, one potential virulence factor that has received little attention in this bacterium is the ability to form biofilm. A bacterial biofilm is defined as a complex community of microorganisms embedded within a self-produced carbohydrate matrix attached to biological or non-biological surfaces [13].

Biofilm formation is an important virulence factor of methicillin-resistant Staphylococcus aureus (MRSA)
Ciomed Central

(c) 2012 DiCicco et al.; licensee BioMed Central Ltd. This is an Open Access article distributed under the terms of the Creative Commons Attribution License (http://creativecommons.org/licenses/by/2.0), which permits unrestricted use, distribution, and reproduction in any medium, provided the original work is properly cited. 
implant-associated infections in humans [13]. It has been suggested that bacteria embedded within a biofilm enter a sessile state which is an important defense mechanism [14]. Biofilm-embedded bacteria are encased in a selfproduced extracellular polysaccharide layer which protects against host immune responses, shear forces and antimicrobial penetration. Infections caused by biofilmforming bacteria pose a tremendous challenge and can be difficult to control due to these protective mechanisms. Bacteria living within biofilms may be highly resistant to antimicrobials that are effective against their free-living counterparts as the minimal inhibitory concentration (MIC) for sessile bacteria within biofilms can be 10 to 1000 times as high as their planktonic form $[15,16]$. Biofilm formation has been hypothesized as one of the reasons for the emergence of a few successful MRSP clones internationally $[17,18]$.

Bacterial biofilms may be of particular concern in veterinary orthopaedic surgery associated with implants [19]. Implants are a risk factor for MRSP SSIs [12] and implant associated infections can be difficult to controlperhaps in large part because of biofilm formation. Therapeutic options available to treat biofilm-associated infections are therefore limited, and removal of infected orthopaedic devices, with the associated morbidity and treatment costs, may be the only viable option [20]. Further development of alternative treatment regimens for biofilm-associated infections is needed.

Clarithromycin (CLA), a macrolide antimicrobial, has been shown to have potent in vitro and in vivo anti-biofilm activity against $S$. aureus and Pseudomonas aeruginosa alone and in combination with other antimicrobials, independent of its inherent antimicrobial activity [13,21-26]. This suggests that CLA could be an option for prevention or eradication of MRSP biofilms. However, biofilm formation (and presumably the factors that regulate biofilm formation) varies between bacterial species, and these factors have not been investigated for MRSP. The objective of this study was to determine the inhibitory effect of clarithromycin on MRSP biofilm formation using a microtiter plate assay.

\section{Methods}

\section{Bacterial isolate screening}

30 epidemiologically unrelated MRSP isolates from dogs from different geographic regions were screened for biofilm production via microtiter plate assay (MPA) [27]. Briefly, overnight cultures were suspended in $5 \mathrm{ml}$ of tryptic soy broth (TSB) supplemented with $1 \%$ glucose to achieve a turbidity equivalent to a 0.5 McFarland standard $\left(\sim 10^{8} \mathrm{CFU} / \mathrm{ml}\right) .200 \mu \mathrm{l}$ of each inoculum was transferred in triplicate to a 96-well polystyrene microtiter plate and incubated under aerobic conditions for $24 \mathrm{~h}$ at $35^{\circ} \mathrm{C}$. Following incubation, the plates were washed three times with phosphate buffered saline (PBS) to remove non-adherent cells and then heat fixed at $60^{\circ} \mathrm{C}$ for 60 minutes. Adhered cells were dyed with $0.1 \%(\mathrm{w} / \mathrm{v})$ of crystal violet for 15 minutes and air dried at room temperature. After resolubilization with 95\% ethanol, optical density (OD) reading of each well of the microtiter plate was assessed, taken at $570 \mathrm{~nm}\left(\mathrm{OD}_{570}\right)$. Readings of replicates for each isolate were averaged and subtracted from the $\mathrm{OD}_{570}$ reading of the negative control (wells containing uninoculated culture medium). $\mathrm{OD}_{570}$ was used as indication of biofilm production. Isolates were classified as biofilm producers if $\mathrm{OD}_{570}$ was $>0.200$ and further classified as strong, moderate, weak, or zero biofilm formers based on their final $\mathrm{OD}_{570}$ reading [28].

\section{Bacterial biofilm evaluation}

Twenty MRSP isolates that were CLA resistant by Kirby Bauer disk diffusion and classified as biofilm producers (net $\mathrm{OD}_{570}>0.200$ ) were chosen for further study. Isolates resistant to CLA were chosen to ensure that any impact of CLA on biofilm formation was independent of antibacterial activity. Isolates were further characterized by sequence analysis of the mec-associated direct repeat unit (dru typing), with dru repeats and types assigned by the dru-typing.org database (http://www.dru-typing.org/ search.php). The impact of CLA on biofilm was assessed by MPA by comparing biofilm production in tryptic soy broth (TSB) supplemented with $1 \%$ glucose and TSB with $1 \%$ glucose plus $8 \mu \mathrm{g} / \mathrm{ml}$ CLA, as described above. To assess biofilm formation and the effect of CLA over time a previously screened high-biofilm forming isolate was chosen and 10 biological replicates assessed at 4, 8, 12,16 and $24 \mathrm{~h}$ using the methods described above.

\section{Statistical methods}

A student's t-test was performed to compare groups with a $\mathrm{P}<0.05$ being considered significant. Statistical analysis was performed on commercially available software (SAS 9.2 TS Level 2M3; SAS Institute Inc., N.C., U.S.A).

\section{SEM protocol}

Scanning electron microscopy (SEM) was used to examine the effect of CLA on MRSP adherence and biofilm production on orthopaedic bone screws. Briefly, an overnight culture of a high biofilm producing isolate of MRSP was inoculated into TSB with $1 \%$ glucose and TSB with $1 \%$ glucose $+8 \mu \mathrm{g} / \mathrm{ml}$ CLA. 316 LVM stainless-steel $20 \mathrm{~mm}$ orthopaedic bone screws (Veterinary Orthopaedic Implants, St. Augustine, FL, USA) were added to $5 \mathrm{ml}$ of a 0.5 McFarland standard suspension of MRSP with and without CLA and incubated for 24 hours aerobically at $35^{\circ} \mathrm{C}$. The screws were qualitatively evaluated at $4,8,12$, 16 , and $24 \mathrm{~h}$ of incubation. Each screw was washed 
with PBS, fixed at room temperature with $2.5 \%$ glutaraldehyde for $24 \mathrm{~h}$ and rinsed in Sorensen's phosphate buffer three times for 15 min each. The screws were post-fixed with $1 \%$ osmium tetroxide for $30 \mathrm{~min}$ at room temperature, washed in Sorensen's phosphate buffer twice for $15 \mathrm{~min}$ each, passed through an ethanol gradient (50\%, $70 \%, 80 \%, 90 \%$, and $99.5 \%$ ), critical-point dried and finally sputter coated with gold. Screws were then imaged using a Hitachi S-570 scanning electron microscope at varying magnification and angles. Images were used to qualitatively assess and preliminarily compare bacterial adherence and the presence of adhered biofilm matrix.

\section{Results}

The twenty CLA-resistant isolates had $\mathrm{OD}_{570}$ readings ranging from 0.206 to 2.64 (Figure 1). There were 3 different $d r u$ types, corresponding to the two main international MRSP clones (Table 1) [29]. Of the twenty selected isolates $15 \%, 35 \%$, and $50 \%$ were categorized as having strong, moderate, or low biofilm adherence properties, respectively (Table 1). There was no impact of CLA on MRSP biofilm formation on polystyrene, with a mean $\mathrm{OD}_{570}+/-\mathrm{SD}$ of the 20 MRSP isolates with and without CLA of $1.0+/-0.63$ and $1.1+/-0.59$, respectively $(\mathrm{P}=0.5216)$. Biofilm formation by high biofilm forming strain, MRSP A12, was evident by 4 hours of incubation and increased over time until $18 \mathrm{~h}$ (Figure 2).

Qualitative evaluation of micrographs produced by SEM of surgical 316 LVM orthopaedic bone screws revealed the ability of MRSP to form biofilm on the surface of and between the screw threads. Adherent bacteria were evident by $4 \mathrm{~h}$ of infection with exopolysaccaride in variable amounts (Figure 3). Visually, CLA did not appear to inhibit MRSP adherence and biofilm formation. Nonhomogenous biofilm formation was evident, with focal biofilm accumulation and circular deposition of biofilm evident on screw heads (Figure 4).

\section{Discussion}

The ability of MRSP to form biofilm may be an important virulence factor and while it is closely related to MRSA, it appears that there are important cross-species differences. While biofilm production was common amongst this collection of MRSP isolates from different major clones and geographic regions, there was no evidence that CLA inhibits biofilm formation, in contrast to previous reports on MRSA [13,22,23]. Accordingly, results do not support the use of CLA for prevention of biofilm formation, and since there was no significant impact on biofilm formation regardless of classification, it is unlikely that CLA would have any impact on biofilm eradication.

CLA resistant strains of MRSP were chosen for this study to ensure that any impact of CLA was from its anti-biofilm effect, not simply from inhibition of bacterial growth. The Clinical and Laboratory Standards Institute interpretive breakpoint for clarithromycin resistance $(\geq 8 \mu \mathrm{g} / \mathrm{ml})$ [30] was chosen to represent a breakpoint concentration that is readily achieved through in vitro studies. One cannot exclude the possibility that an impact might have been present with higher

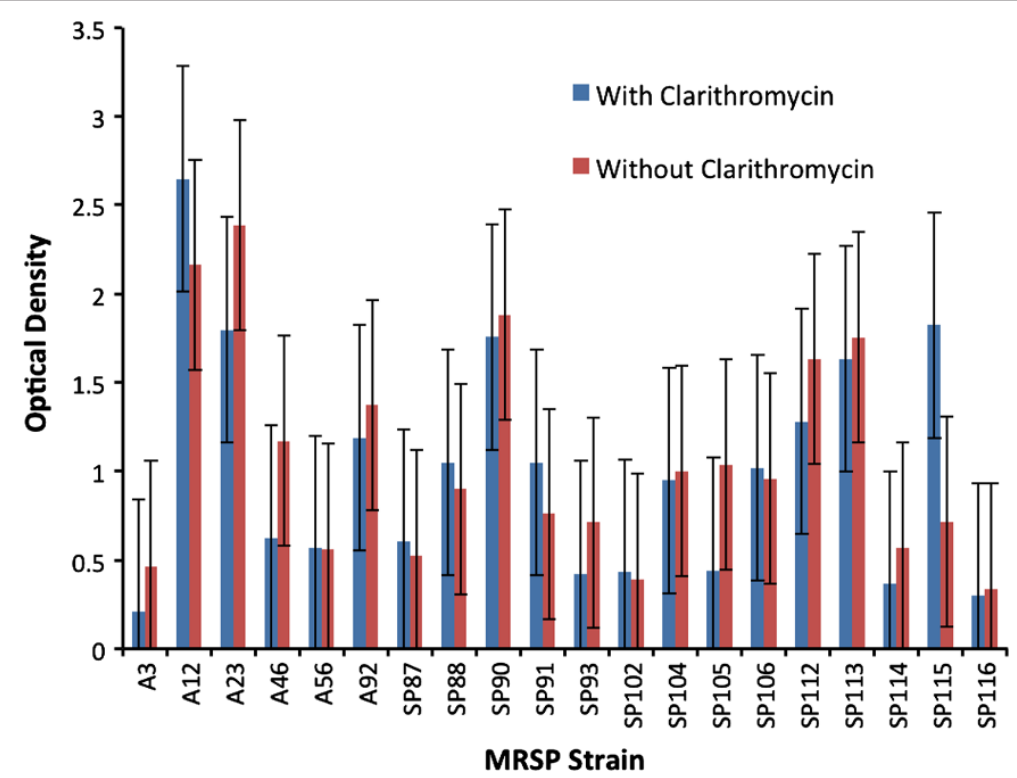

Figure 1 Effect of Clarithromycin on MRSP after 24 h. Biofilm forming potential of 20 MRSP strains and the effect of clarithromycin after $24 \mathrm{~h}$ as revealed by Crystal Violet Microtiter Assay. Mean $\mathrm{OD}_{570}+/-$ SD of the MRSP isolates with and without clarithromycin were $1.0+/-0.63$ and $1.1+/-0.59$, respectively. Clarithromycin had no significant effect $(P=0.5126)$ on MRSP biofilm formation. 
Table 1 Origin, biofilm adherence classification, direct repeat unit $(d r u)$ and sequence type of study isolates

\begin{tabular}{|c|c|c|c|c|}
\hline $\begin{array}{l}\text { Isolate } \\
\text { selected }\end{array}$ & $\begin{array}{l}\text { Adherence } \\
\text { capabilities }\end{array}$ & $\begin{array}{l}\text { Dru } \\
\text { typing }\end{array}$ & $\begin{array}{l}\text { Sequence } \\
\text { type }\end{array}$ & $\begin{array}{l}\text { Origin } \\
\text { location }\end{array}$ \\
\hline$\overline{\mathrm{A} 3}$ & LOW & $9 a$ & 71 & U.S.A \\
\hline $\mathrm{A} 12$ & STRONG & $10 \mathrm{~h}$ & 68 & U.S.A \\
\hline A23 & STRONG & $10 a$ & 68 & U.S.A \\
\hline A46 & MODERATE & $9 a$ & 71 & U.S.A \\
\hline A56 & LOW & $9 a$ & 71 & U.S.A \\
\hline A92 & MODERATE & $9 a$ & 71 & U.S.A \\
\hline SP87 & LOW & $9 a$ & 71 & Canada \\
\hline SP88 & LOW & $9 a$ & 71 & Canada \\
\hline SP90 & STRONG & $9 a$ & 71 & Canada \\
\hline SP91 & LOW & $9 a$ & 71 & Canada \\
\hline SP93 & LOW & $9 a$ & 71 & Canada \\
\hline SP102 & LOW & $11 a$ & 68 & Canada \\
\hline SP104 & MODERATE & $10 \mathrm{~h}$ & 68 & Canada \\
\hline SP105 & MODERATE & $10 \mathrm{~h}$ & 68 & Canada \\
\hline SP106 & MODERATE & $9 a$ & 71 & Canada \\
\hline SP112 & MODERATE & $9 a$ & 71 & Canada \\
\hline SP113 & MODERATE & $9 a$ & 71 & Canada \\
\hline SP114 & LOW & $9 a$ & 71 & Canada \\
\hline SP115 & LOW & $9 a$ & 71 & Canada \\
\hline SP116 & LOW & $9 a$ & 71 & Canada \\
\hline
\end{tabular}

Dru typing of chosen biofilm forming isolates of MRSP reveals a representative population of strains commonly found in veterinary hospitals across North America. Adherence capabilities were determined based on the model developed by Stepanovic et al., 2000. concentrations of CLA, but the clinical relevance would be questionable.

The mechanism of biofilm prevention by macrolides seen in MRSA and other bacteria is not completely understood but current studies speculate that they also act through modification of the immune system's inflammatory response to infection, and/or through a direct effect on bacterial virulence [24,26,31]. For this reason it cannot be excluded that CLA may be effective in vivo, however in vitro studies involving MRSA still support a preventative effect on biofilm formation [13]. It has also previously been shown that macrolide antibiotics affect quorum sensing - the initial mechanism behind bacterial biofilm formation and cell-cell communication-within the biofilm leading to reduced polysaccharide synthesis and instability of biofilm architecture [20,25,32].

It is possible that CLA does not impose a preventative biofilm forming mechanism on MRSP, as seen in MRSA, due to genetic variances not yet revealed between the two species. Currently, ica is considered to be the major operon responsible for staphylococcal biofilm formation [33] but its study in MRSP strains has not been performed. Alternative pathways for quorum sensing could also cause the mitigation of the previously demonstrated effect of macrolides. Dru typing results suggest a varying geographic distribution and representative chosen isolate population across the two current internationally predominant MRSP strains, ST68 and ST71 (Table 1) [34]. From this we can infer that genetic differences and therefore the effect of CLA on different strains of MRSP are likely minimal.

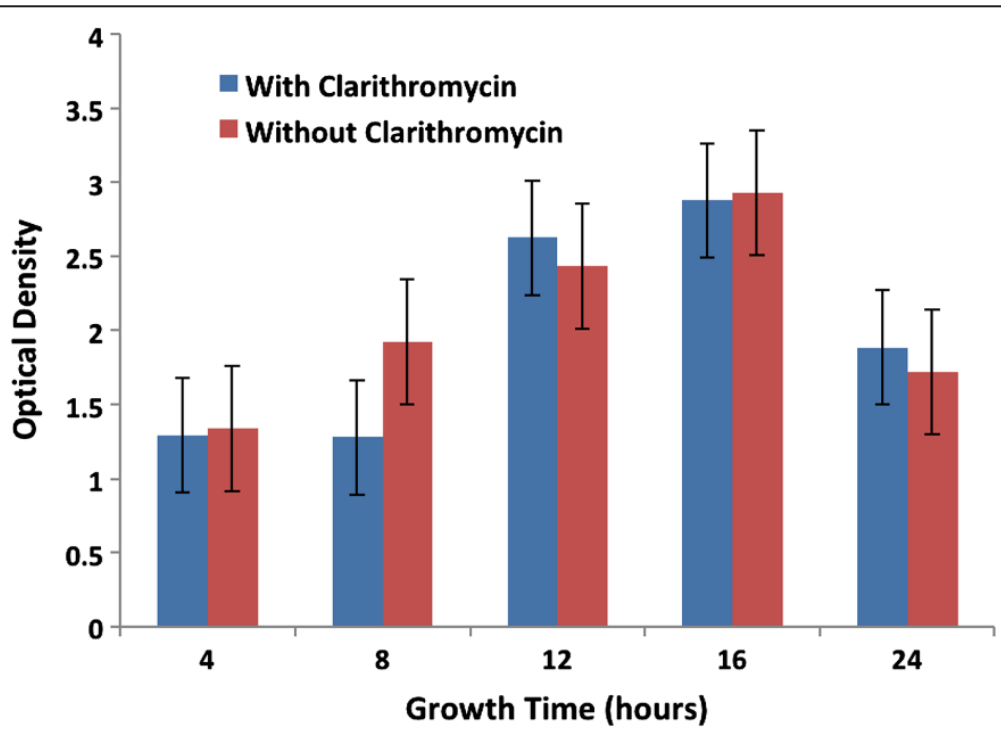

Figure 2 Effect of Clarithromycin on MRSP over time. Biofilm forming potential of MRSP A12 strain and the effect of clarithromycin over time as revealed by Crystal Violet Microtiter Plate Assay. Clarithromycin had no significant effect on MRSP biofilm formation between 4 and $24 \mathrm{~h}$. 

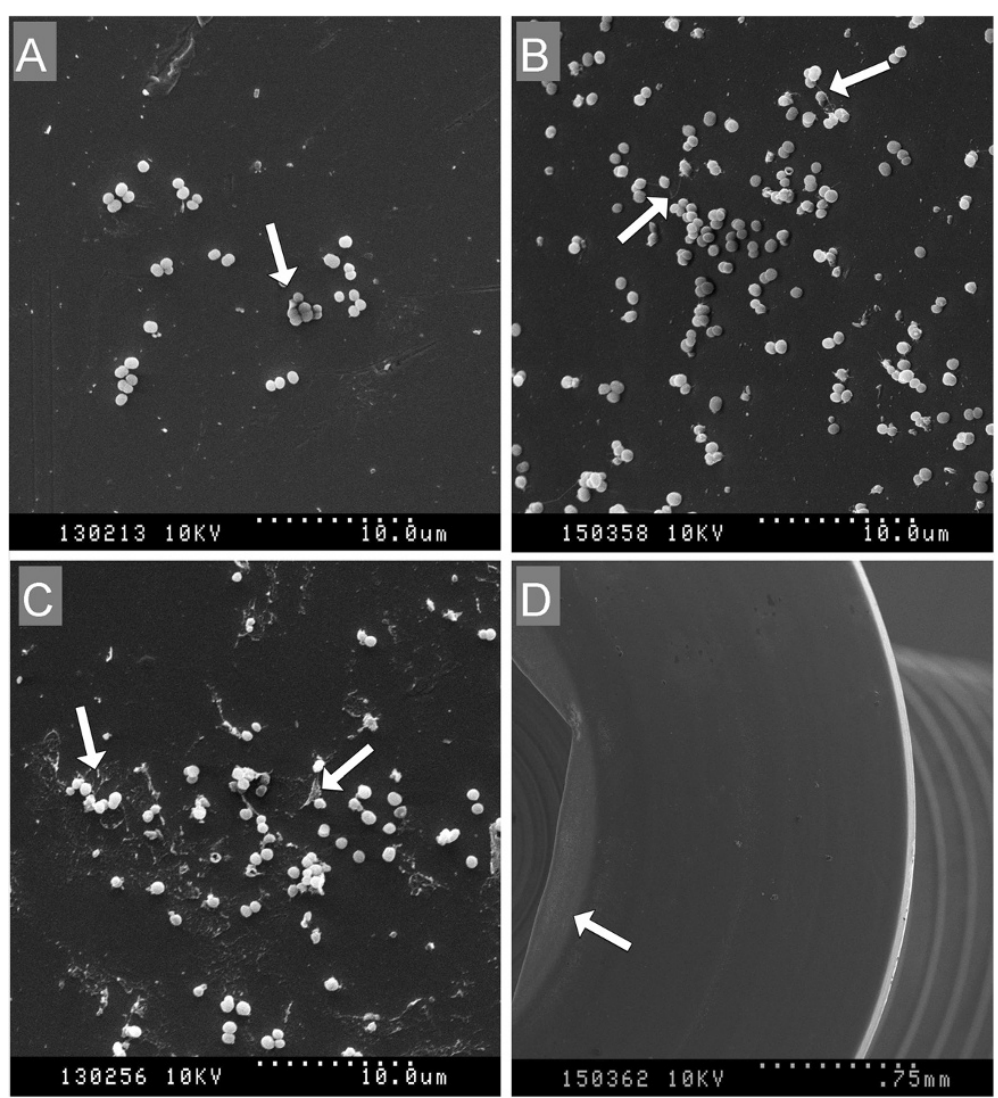

Figure 3 SEM images of biofilms formed on canine orthopaedic bone screws treated with addition of clarithromycin. (A) Showing minimal MRSP biofilm production at $4 \mathrm{~h}$ (B) showing increased EPS (extracellular polymeric substance) and morphological changes characteristic to biofilms at $12 \mathrm{~h}$ (C) firm attachment of MRSP biofilm, further increase of EPS and clumping of cells at $24 \mathrm{~h}$ (D) MRSP biofilm growth concentrated to specific areas on the screw head.
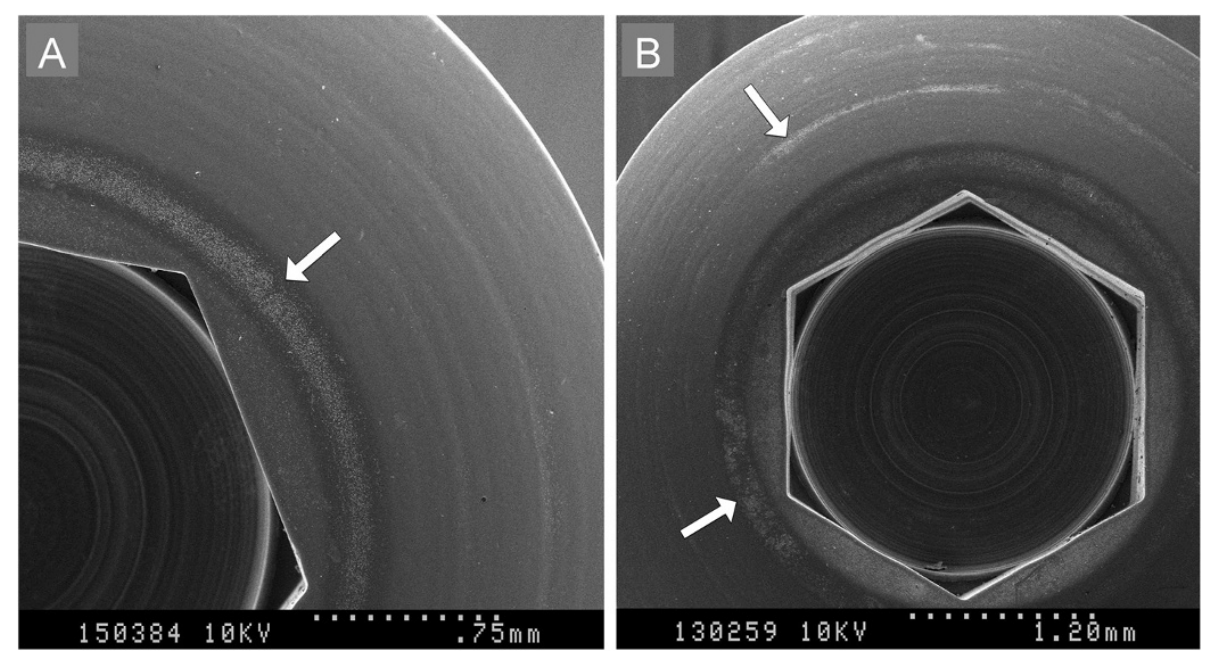

Figure 4 SEM images of biofilm adherence around circular striations from machining on canine orthopaedic bone screws. (A) MRSP biofilm growth at $8 \mathrm{~h}$ without CLA addition (B) MRSP biofilm growth at $24 \mathrm{~h}$ without CLA addition. 
Time assessed biofilm development, while only one isolate was studied, suggests that biofilm formation occurs rapidly in vitro, since adherent bacteria and exopolysaccaride matrix were evident within $4 \mathrm{~h}$ by both the crystal violet MPA and through qualitative SEM evaluation of growth on surgical screws. Objective assessment of the impact of CLA on biofilm formation on screws was not possible since only one isolate was studied in a qualitative manner, yet these subjective data are in support of the crystal violet MPA and provide further evidence of a lack of efficacy of CLA for prevention of biofilm formation. The irregular biofilm patterns on screws, most notably the circular biofilm accumulations on screw heads, is consistent with preferential biofilm adhesion to invisible surface defects or irregularities in the machining process. This suggests that minor surface alterations, either from inherent defects or damage to implants during placement, could facilitate biofilm attachment in vivo.

In vitro evaluations of CLA on MRSP biofilm formation were performed on polystyrene and one orthopedically relevant biomaterial providing potential limitations to this study. Although no significant inhibitory effect of CLA on these materials was found, material properties of biofilm attachment sites could play a minor role in the susceptibility to and persistence of staphylococci infections [33]. Combinational therapy with CLA and varying antimicrobials has also been shown to have appreciable effects against MRSA biofilm formation $[13,22,23]$. Because of the potential benefit to biofilm formation prevention and the safety of macrolides shown in long-term randomized macrolide therapy, further study and use of CLA in combinational therapy and on varying biomaterials is recommended [20].

Large variances in both the amount of bacteria and antimicrobial in suspension in the $200 \mu \mathrm{l}$ sample before addition to the microtiter plate could add to uncertainty in crystal violet microtiter plate assay results as previously described [27]. Optical determination of 0.5 McFarland and quick doubling-time of S. pseudintermedius could also contribute to the large standard deviations found for each averaged isolate $\mathrm{OD}_{570}$ reading. Microtiter plate washing techniques, as described in Stepanovic et al., also leave room for interpretation and could lead to the removal of transient bacterial biofilms, further adding to the variance in quantitative results for each isolate. Although the two currently most prevalent MRSP strains internationally were represented (ST68 and ST71) other biofilm forming strains of MRSP susceptible to the biofilm prevention mechanism in CLA might exist. Finally, the SEM study only accounts for one of 20 screened isolates across 11 biological replicates. Though the analysis was only for comparison the images are not representative of strains seen in the MPA.

\section{Conclusions}

Results suggest that CLA does not inhibit MRSP biofilm formation on polystyrene, independent of the antimicrobial activity when evaluated through a crystal violet assay. Qualitative SEM imaging results also suggest that adhesion and formation of MRSP biofilms begin within $4 \mathrm{~h}$ of infection on stainless-steel with no inhibitory effect by CLA. However, CLA may inhibit MRSP biofilm on other surfaces such as titanium based implants. In vivo and additional in vitro studies evaluating the effect of CLA alone and in combination with other antimicrobials on MRSP biofilm formation through crystal violet assays and other biomaterials are warranted.

\section{Competing interest}

All authors declare that they have no competing interests.

\section{Authors' contributions}

MD conducted the microtitre plate assay experiments, acquired SEM images and drafted the manuscript. SN, AS, and SW contributed in the conceptual design of the experiments. All authors read and approved the final manuscript.

\section{Acknowledgements}

This work was supported in part by funding from the Natural Sciences and Engineering Research Council of Canada (NSERC), the Canadian Institutes for Health Research $(\mathrm{CIHR})$, and the OVC Pet Trust Fund.

\section{Author details}

${ }^{1}$ School of Engineering, University of Guelph, Ontario, Canada. ${ }^{2}$ Department of Clinical Studies, Ontario Veterinary College, University of Guelph, Ontario, Canada. ${ }^{3}$ Department of Pathobiology, Ontario Veterinary College, University of Guelph, Ontario, Canada.

Received: 29 June 2012 Accepted: 7 November 2012

Published: 21 November 2012

\section{References}

1. Weese JS: A review of multidrug resistant surgical site infections. Vet Comp Orthop Traumatol 2008, 21(1):1-7.

2. Vasseur PB, Levy J, Dowd E, Eliot J: Surgical wound infection rates in dogs and cats data from a teaching hospital. Vet Surg 1988, 17(2):60-64.

3. Nicholson M, Beal M, Shofer F, Brown DC: Epidemiologic evaluation of postoperative wound infection in clean-contaminated wounds: a retrospective study of 239 dogs and cats. Vet Surg 2002, 31(6):577-581.

4. Eugster S, Schawalder P, Gaschen F, Boerlin P: A prospective study of postoperative surgical site infections in dogs and cats. Vet Surg 2004, 33(5):542-550.

5. Abraham JL, Morris DO, Griffeth GC, Shofer FS, Rankin SC: Surveillance of healthy cats and cats with inflammatory skin disease for colonization of the skin by methicillin-resistant coagulase-positive staphylococci and Staphylococcus schleiferi ssp. schleiferi. Vet Dermatol 2007, 18(4):252-259.

6. Griffeth GC, Morris DO, Abraham JL, Shofer FS, Rankin SC: Screening for skin carriage of methicillin-resistant coagulase-positive staphylococci and Staphylococcus schleiferi in dogs with healthy and inflamed skin. Vet Dermatol 2008, 19(3):142-149.

7. Stefani S, Varaldo PE: Epidemiology of methicillin-resistant staphylococci in Europe. Clin Microbiol Infect 2003, 9(12):1179-1186.

8. Gortel K, Campbell KL, Kakoma I, Whittem T, Schaeffer DJ, Weisiger RM: Methicillin resistance among staphylococci isolated from dogs. Am J Vet Res 1999, 60(12):1526-1530.

9. Vengust M, Anderson ME, Rousseau J, Weese JS: Methicillin-resistant staphylococcal colonization in clinically normal dogs and horses in the community. Lett Appl Microbiol 2006, 43(6):602-606.

10. Weese JS: A review of post-operative infections in veterinary orthopaedic sugery. Vet Comp Orthop Traumatol 2008, 21:99-105. 
11. Chrobak D, Kizerwetter-Swida M, Rzewuska M, Moodley A, Guardabassi L, Binek M: Molecular characterization of Staphylococcus pseudintermedius strains isolated from clinical samples of animal origin. Folia Microbiol (Praha) 2011, 56(5):415-422.

12. Turk R, Singh A, Weese JS: Post-hospital discharge procedure specific surgical site infection surveillance in small animal patients, 2nd ASM/ESCMID conference on methicillin-resistant staphylococci in animals: veterinary and public health implications. Washington DC, USA: 2011.

13. Parra-Ruiz J, Vidaillac C, Rose WE, Rybak MJ: Activities of high-dose daptomycin, vancomycin, and moxifloxacin alone or in combination with clarithromycin or rifampin in a novel in vitro model of Staphylococcus aureus biofilm. Antimicrob Agents Chemother 2010, 54(10):4329-4334.

14. Jefferson KK: What drives bacteria to produce a biofilm? FEMS Microbiol Lett 2004, 236(2):163-173.

15. Cohn LA, Middleton JR: A veterinary perspective on methicillin-resistant staphylococci. J Vet Emerg Crit Care (San Antonio) 2010, 20(1):31-45.

16. Ceri H, Olson ME, Stremick C, Read RR, Morck D, Buret A: The calgary biofilm device: new technology for rapid determination of antibiotic susceptibilities of bacterial biofilms. J Clin Microbio/ 1999, 37(6):1771-1776.

17. Osland AM, Vestby LK, Fanuelsen H, Slettemeas JS, Sunde M: Clonal diversity and biofilm-forming ability of methicillin-resistant Staphylococcus pseudintermedius. J Antimicrob Chemother 2012, 67(4):841-848

18. Weese JS, van Duijkeren E: Methicillin-resistant staphylococcus aureus and staphylococcus pseudintermedius in veterinary medicine. Vet Microbio/ 2010, 140(3-4):418-429.

19. Costerton JW: Biofilm theory can guide the treatment of device-related orthopaedic infections. Clin Orthop Relat Res 2005, 437(437):7-11.

20. Parra-Ruiz J, Vidaillac C, Rybak MJ: Macrolides and staphylococcal biofilms. Rev Esp Quimioter 2012, 25(1):10-16.

21. Sano M, Hirose T, Nishimura M, Takahashi S, Matsukawa M, Tsukamoto T: Inhibitory action of clarithromycin on glycocalyx produced by MRSA. $J$ Infect Chemother 1999, 5(1):10-15.

22. Fujimura S, Sato T, Mikami T, Kikuchi T, Gomi K, Watanabe A: Combined efficacy of clarithromycin plus cefazolin or vancomycin against Staphylococcus aureus biofilms formed on titanium medical devices. Int J Antimicrob Agents 2008, 32(6):481-484.

23. Fujimura S, Sato T, Kikuchi T, Zaini J, Gomi K, Watanabe A: Efficacy of clarithromycin plus vancomycin in mice with implant-related infection caused by biofilm-forming Staphylococcus aureus. J Orthop Sci 2009, 14(5):658-661.

24. Tateda K, Ishii Y, Kimura S, Horikawa M, Miyairi S, Yamaguchi K: Suppression of Pseudomonas aeruginosa quorum-sensing systems by macrolides: a promising strategy or an oriental mystery? J Infect Chemother 2007, 13(6):357-367

25. Skindersoe ME, Alhede M, Phipps R, Yang $L$, Jensen PO, Rasmussen TB, Bjarnsholt T, Tolker-Nielsen T, Hoiby N, Givskov M: Effects of antibiotics on quorum sensing in pseudomonas aeruginosa. Antimicrob Agents Chemother 2008, 52(10):3648-3663.

26. Cirioni O, Ghiselli R, Silvestri C, Minardi D, Gabrielli E, Orlando F, Rimini M, Brescini L, Muzzonigro G, Guerrieri M, et al: Effect of the combination of clarithromycin and amikacin on pseudomonas aeruginosa biofilm in an animal model of ureteral stent infection. J Antimicrob Chemother 2011, 66(6):1318-1323.

27. Stepanovic S, Vukovic D, Hola V, Di Bonaventura G, Djukic S, Cirkovic I, Ruzicka F: Quantification of biofilm in microtiter plates: overview of testing conditions and practical recommendations for assessment of biofilm production by staphylococci. APMIS 2007, 115(8):891-899.

28. Stepanović S, Vuković D, Dakić I, Savić B, Švabić-Vlahović M: A modified microtiter-plate test for quantification of staphylococcal biofilm formation. J Microbiol Methods 2000, 40(2):175-179.

29. Ruscher C, Lubke-Becker A, Semmler T, Wleklinski CG, Paasch A, Soba A, Stamm I, Kopp P, Wieler LH, Walther B: Widespread rapid emergence of a distinct methicillin- and multidrug-resistant Staphylococcus pseudintermedius (MRSP) genetic lineage in Europe. Vet Microbiol 2010, 144(3-4):340-346.

30. Clinical and Laboratory Standards Institute: Performance standards for antimicrobial disk and dilution susceptibility tests for bacteria isolated from animals - Third Edition: Approved Standard M31-A. Wayne, PA, USA: CLSI; 2008.
31. Hoffmann N, Lee B, Hentzer M, Rasmussen TB, Song Z, Johansen HK, Givskov M, Hoiby N: Azithromycin blocks quorum sensing and alginate polymer formation and increases the sensitivity to serum and stationarygrowth-phase killing of Pseudomonas aeruginosa and attenuates chronic P. aeruginosa lung infection in Cftr(-/-) mice. Antimicrob Agents Chemother 2007, 51(10):3677-3687.

32. Ichimiya T, Takeoka K, Hiramatsu K, Hirai K, Yamasaki T, Nasu M: The influence of azithromycin on the biofilm formation of pseudomonas aeruginosa in vitro. Chemotherapy 1996, 42(3):186-191.

33. Hudetz D, Ursic Hudetz S, Harris LG, Luginbuhl R, Friederich NF, Landmann R: Weak effect of metal type and ica genes on staphylococcal infection of titanium and stainless steel implants. Clin Microbiol Infect 2008, 14(12):1135-1145.

34. Perreten V, Kadlec K, Schwarz S, Gronlund Andersson U, Finn M, Greko C, Moodley A, Kania SA, Frank LA, Bemis DA, et al: Clonal spread of methicillin-resistant Staphylococcus pseudintermedius in Europe and North America: an international multicentre study. J Antimicrob Chemother 2010, 65(6):1145-1154.

doi:10.1186/1746-6148-8-225

Cite this article as: DiCicco et al.: Efficacy of clarithromycin on biofilm formation of methicillin-resistant Staphylococcus pseudintermedius. BMC Veterinary Research 2012 8:225.

\section{Submit your next manuscript to BioMed Central and take full advantage of:}

- Convenient online submission

- Thorough peer review

- No space constraints or color figure charges

- Immediate publication on acceptance

- Inclusion in PubMed, CAS, Scopus and Google Scholar

- Research which is freely available for redistribution 